\title{
A simple, high-yield, apparatus for NEG coating of vacuum beamline elements
}

\author{
G. Ron ${ }^{a *}$ R. Oort ${ }^{b}$, and D. Lee ${ }^{b}$ \\ ${ }^{a}$ Nuclear Science Division, Lawrence Berkeley National Laboratory, CA 94720 \\ (GRon@lbl.gov) \\ ${ }^{b}$ Engineering Division, Lawrence Berkeley National Laboratory, CA 94720
}

\begin{abstract}
Non-Evaporable Getter (NEG) materials are extremely useful in vacuum systems for achieving Ultra High Vacuum. Recently, this materials have been used to coat the inner surfaces of vacuum components, acting as an internal, passive, vacuum pump.

We have constructed a low cost apparatus, which allows coating of very small diameter vacuum tubes, used as differential pumping stages. Despite the relative ease of construction, we are routinely able to achieve high coating yields. We further describe an improvement to our system, which is able to achieve the same yield, at an even lower complexity by using an easily manufactured permanent magnet arrangement. The designs described are extendible to virtually any combination of length and diameter of the components to be coated.
\end{abstract}

\footnotetext{
${ }^{*}$ Corresponding author.
} 


\section{Introduction}

Non-evaporable Getter (NEG) material is commonly used in vacuum system in order to achieve extreme high vacuum. NEG material, after being heat activated chemically pumps gases commonly occurring in vacuum systems, such as $\mathrm{H}_{2}, \mathrm{CO}$, and $\mathrm{CO}_{2}$. New techniques for using NEG have been development, in which the NEG material is used to coat the vacuum system inner surfaces, thus providing an integrated pumping system. Such a design has the additional benefit of reducing secondary electron yield, photon stimulated desorption and electron stimulated desorption, and has been employed, for example, at the LHC, and ESRF [1, 2].

Of the available NEG materials, the ones which have the lowest activation temperature (and hence can be activated as part of the standard bakeout procedure in vacuum systems) are TiZrV compound, which display low activation temperature and high pumping speeds $[3,4,5]$.

Typically, the vacuum systems are coated by DC magnetron sputtering, in which a combination of crossed electric and magnetic fields in used to confine a plasma which sputters ions from a cathode made of the desired material onto the vacuum chamber walls. For coating beampipe elements (cylindrical vacuum chambers), an external air-core solenoid is used to provide the requisite magnetic field, while an axial cathode is used to provide the crossed electric field and the material to be deposited. The confined plasma is usually generated by the introduction of $\mathrm{Kr}$ or $\mathrm{Ar}$ gas. Several groups have shown that magnetron DC sputtering is an effective method to coat NEG material onto vacuum components [5, 6], in particular, by using a cathode made by twisting thin $\mathrm{Ti}$, $\mathrm{V}$, and $\mathrm{Zr}$ wires. The field strength required for the magnetron sputtering is related to the operating voltage and the chamber radius as [7]:

$$
B R_{c}>10 V^{0.5}[\mathrm{G} \cdot \mathrm{cm}]
$$

where $\mathrm{B}$ is the magnetic field, $R_{c}$ is the cylindrical chamber radius, and $\mathrm{V}$ is the operating voltage.

Currently, NEG coating is used to provide internal pumping of vacuum components, reducing the need for external pumping. A yet unaddressed benefit is the use of NEG coating in differential pumping stages in order to enhance the effectiveness of the differential pumping. In particular, the differential pumping stages in use are thin tubes connecting larger bore vacuum components, a configuration at odds with the addition of external pumping components.

\section{Apparatus Design}

We have designed a low cost system, using an axial cathode made from twisted wires, to coat thin, long, vacuum tubes used as differential pumping stages in an ion beamline under construction at the Lawrence Berkeley 88" Cyclotron.

The apparatus was constructed using two four-way 2.75 " ConFlat crosses, connected by a vertical vacuum tube which was the element to be coated a sapphire window for viewing the plasma, and a high power feedthrough, connected to the twisted wire cathode. The bottom cross was connected to a high purity Ar feedline, fed through a mass flow controller, a $4001 / \mathrm{sec}$ turbomolecular pump (Pfeiffer HiPace 400), a nude ion gauge, and a convectron guage for background pressure measurements. 
The apparatus was designed to allow coating of cylindrical chamber in the 0.5 " to 1.5 " diameter range, with a typical operating voltage of $\sim 500 \mathrm{~V}$, requiring a magnetic field greater $\sim 350 \mathrm{G}$ (see Eq. 1.1).

The axial magnetic field was provided by a $15.2 \mathrm{~cm}$ long, $7.6 \mathrm{~cm}$ diameter, air core solenoid, comprised of two layers of approximately 36 windings each of $3 \mathrm{~mm}$ diameter copper tubing. The tubes were coated with Kapton tape for insulation and separately wired to a 200A DC power supply. Cooling for the solenoid was provided by flowing deionized water through the copper tubing. At peak field, the magnet used 200A of current and had a voltage drop of approximately $6.25 \mathrm{~V}$, requiring less than $1.5 \mathrm{~kW}$ of cooling power.

Since the design is meant to be used with long and thin differential pumping stages it requires either a long solenoid or a movable solenoid design. In order to reduce the weight, complexity, cooling, and current requirements of the magnet we opted to design the system in a way which will allow the magnet to be moved along the axis of the tube to be coated, at the expense of increasing the time required by a factor equal to the length of the tube over the length of the magnet. The magnet was suspended from a chainfall arrangement with a clamp slightly larger than the tube diameter in order to align the magnet along the axis of the tube. The coating was then achieved in stages, the magnet being moved approximately $90 \%$ of its $15 \mathrm{~cm}$ length between stages.

A maximum current the magnet generated a field of $400 \mathrm{G}$, easily accommodating the required $B>350 \mathrm{G}$. Figures 1 and 2 show a schematic and photograph of the apparatus.

The base pressure was maintained by adjusting the turbomolecular pump speed to be at $\approx$ $10^{-7}$ Torr. During the coating process the Ar pressure in the chamber was roughly 4 mTorr.

\section{Yield Measurements}

In order to measure the yield of deposited NEG material we placed a glass slide (coupon) flush with the chamber wall. A section of the slide was covered by a second glass slide, creating a step in the deposited material when top slide was removed after deposition. This step makes possible profilometer measurements of the thickness of the deposited film. This measurement can then be used to deduce the deposition rate for the NEG material. Figure 3 shows the coupon used to measure the deposition rate, the two overlapping glass slides can be seen.

Table 1 details the operating conditions and measured deposition rates for several tube diameters. The measured deposition rates should be contrasted with typical deposition rates for NEG coating in similar systems, for example, in Ref [5] deposition rates of $360 \AA / \mathrm{h}$ and $3600 \AA / \mathrm{h}$ were reported for two different configurations of the coating system. It is likely that the significant difference in the deposition rates between our system and the equivalent system used in [5] (System A) stems from the larger diameter cylinder used in [5] which gives a factor of $\sim 17$ in the surface area between the two coated surfaces. The reduction in deposition rate between the different diameters used in our system is due to the lower maximum power which could be used with the thinner cathode wires (for the smaller diameter tubes) without breaking the wire due to overheating, and is partially offset by the reduction in surface area.

X-Ray Diffraction (XRD) measurements were performed on the NEG material deposited in order to determine the composition of the deposited material. Figure 4 shows a typical XRD spectrum, showing the relative abundance of $\mathrm{Ti}, \mathrm{Zr}$, and $\mathrm{V}$ in the deposited material. In all cases 


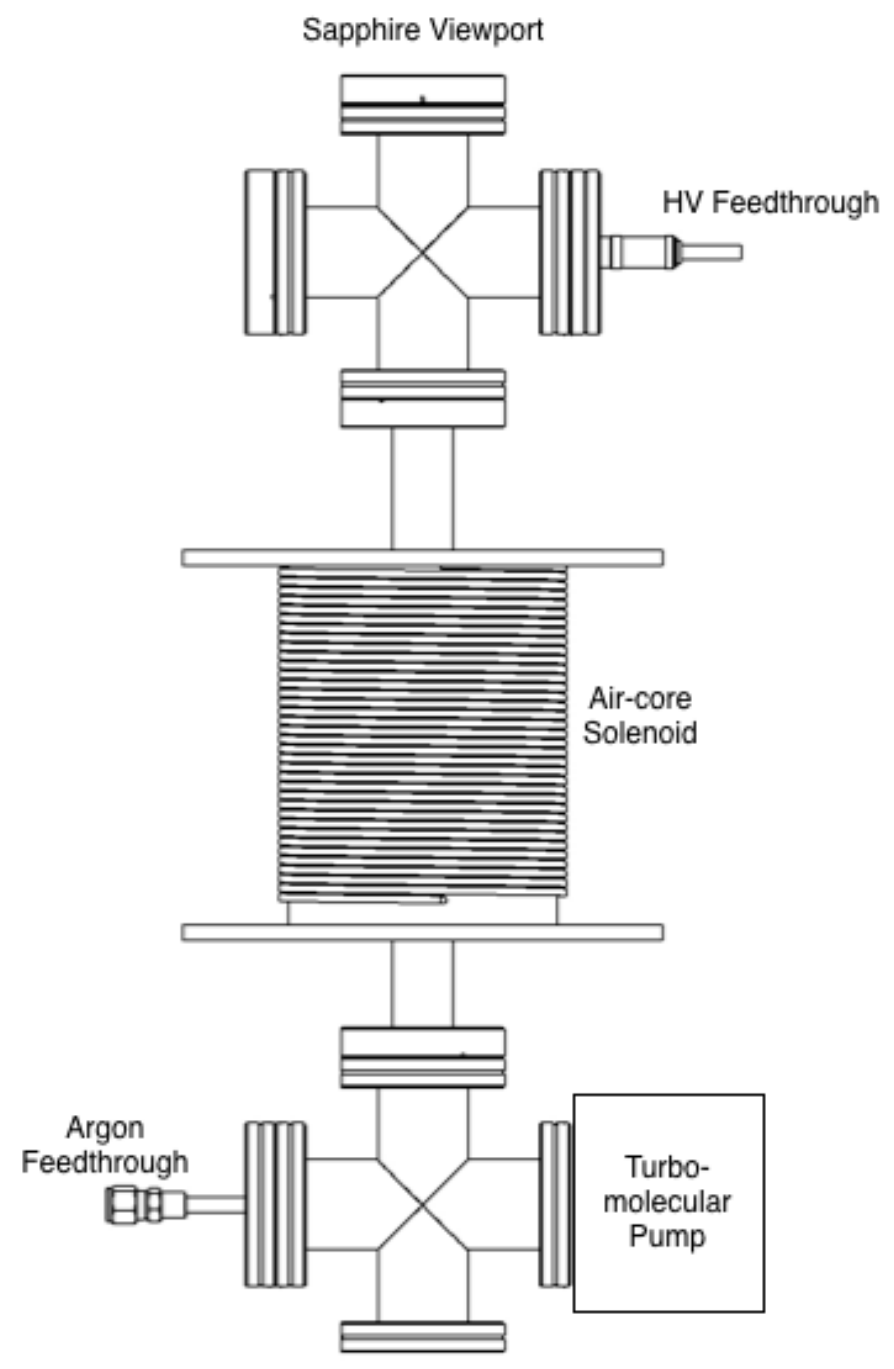

Figure 1. A schematic of the coating apparatus.

\begin{tabular}{|c|c|c|c|c|c|c|}
\hline $\begin{array}{c}\text { Tube } \\
\text { Diameter } \\
(\mathrm{cm})\end{array}$ & $\begin{array}{c}\text { Cathode } \\
\text { Wire Diameter } \\
(\mathrm{mm})\end{array}$ & $\begin{array}{c}\text { Cathode } \\
\text { Wire Length } \\
(\mathrm{mm})\end{array}$ & $\begin{array}{c}\text { Power } \\
\text { (W) }\end{array}$ & Voltage & $\begin{array}{c}\text { Ar flow rate } \\
\text { (SCCM) }\end{array}$ & Deposition rate \\
\hline 3.81 & 1 & 355.6 & 60 & $285-345$ & 100 & $12700 \pm 100$ \\
\hline 2.54 & 0.5 & 558.8 & 15 & $370-400$ & 100 & $3600 \pm 100$ \\
\hline 1.27 & 0.5 & 558.8 & 15 & $300-450$ & 190 & $10900 \pm 100$ \\
\hline
\end{tabular}

Table 1. Operating conditions and measured deposition rates.

the measured composition showed nearly equal amount (at $\%$ ) of the three elements. Figure5 show 


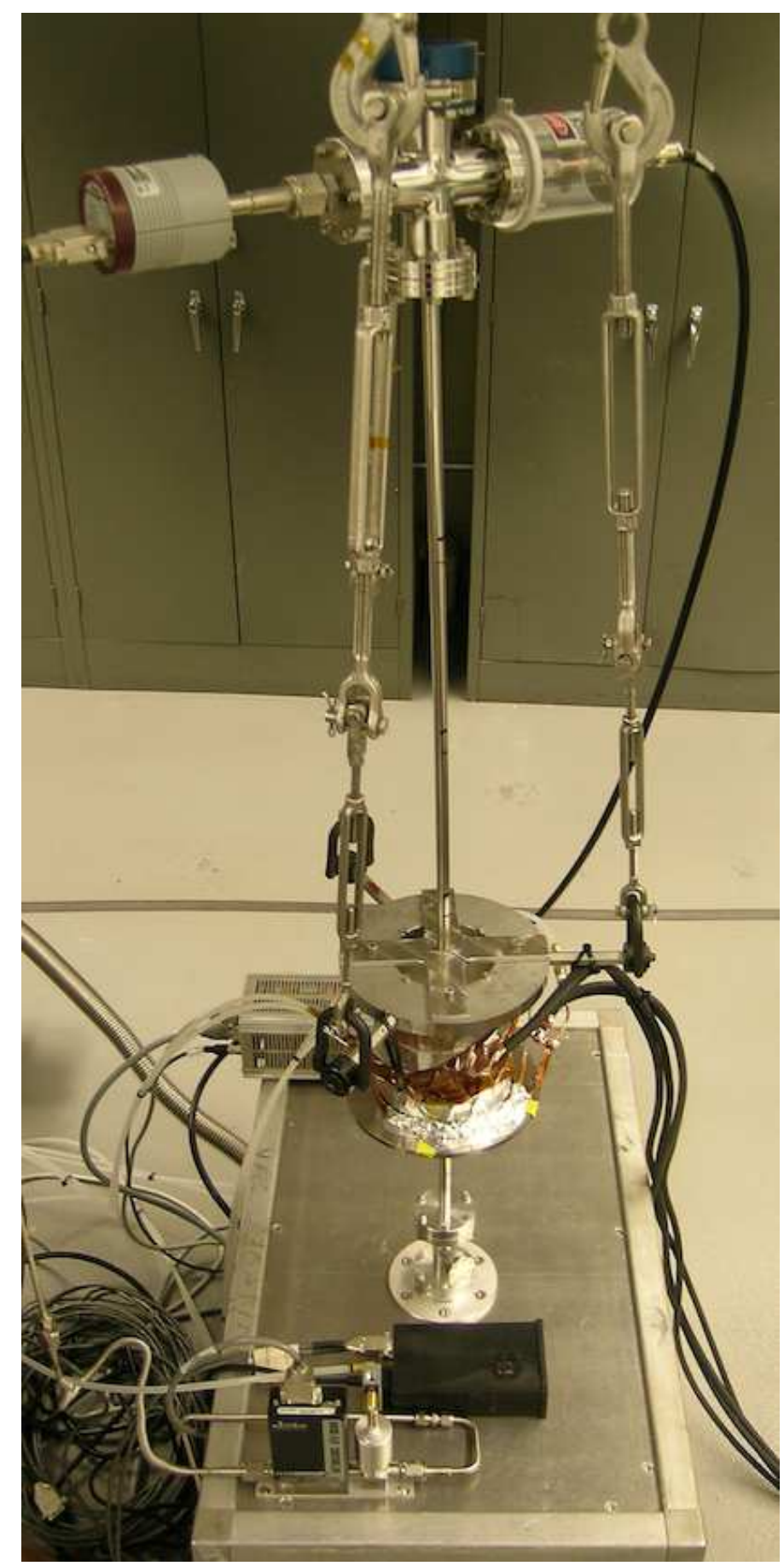

Figure 2. A picture of the coating apparatus, the magnet can be seen surrounding a thin tube and suspended from the chainfall arrangement.

a typical Scanning Electron Microscope (SEM) image at 100k magnification of the deposited NEG film, individual grains and void between the grains can be seen. We have also compared the results with an Energy-dispersive X-ray (EDX) measurement of the deposited material, the results from 


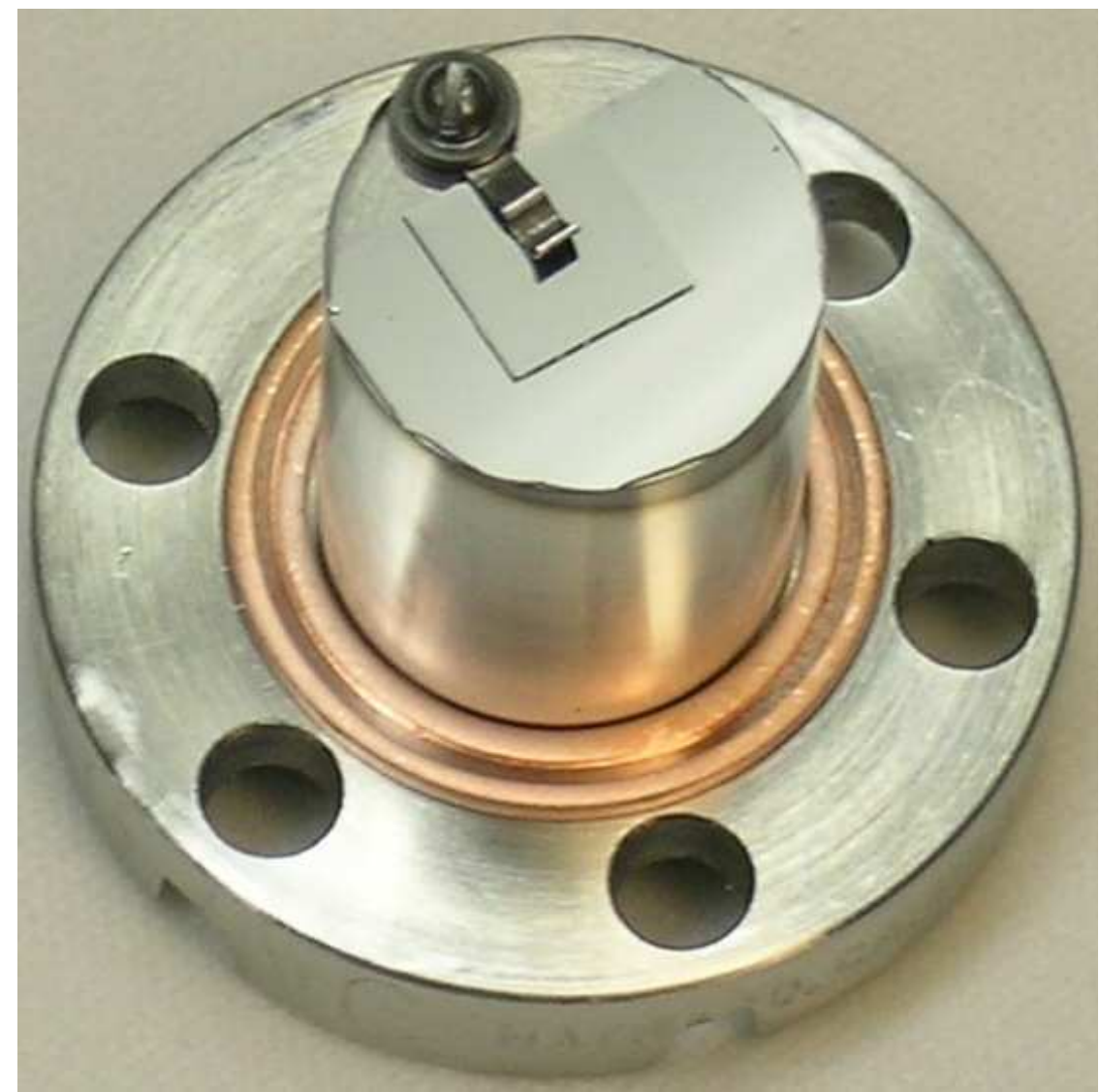

Figure 3. A coupon used to measure the deposition rate of the NEG material.

the EDX measurement shown in Figure 6 confirm the nearly equal amounts of the three materials in the foil composition.

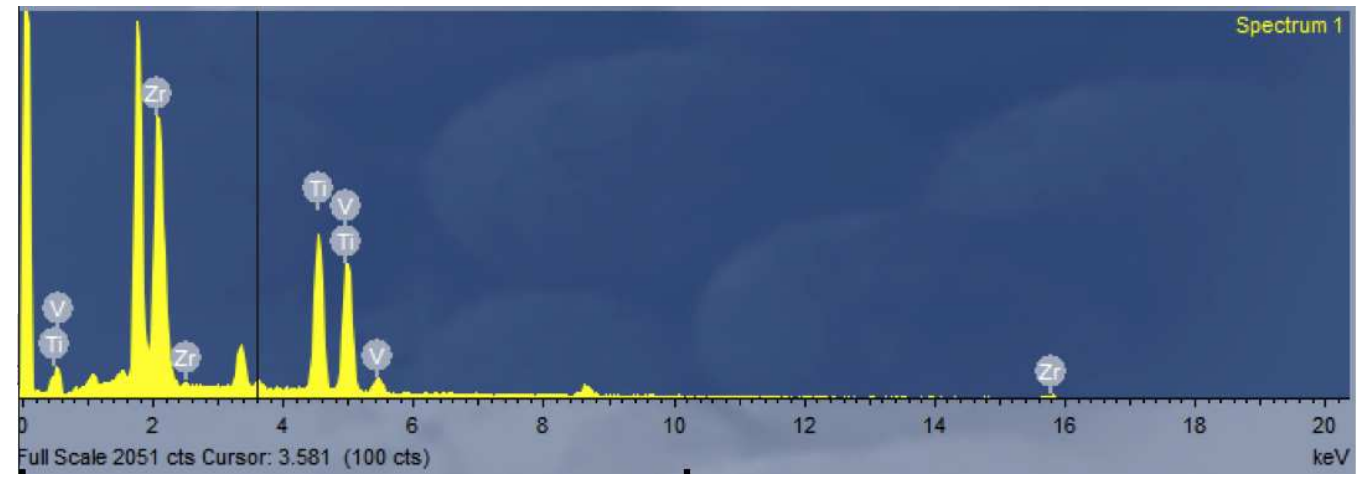

Figure 4. A typical XRD scan of the deposited NEG material. 
Figure 5. A typical SEM image of the deposited NEG film at 100k magnification.

\section{Full scale counts: 419}

09302010a_pt1

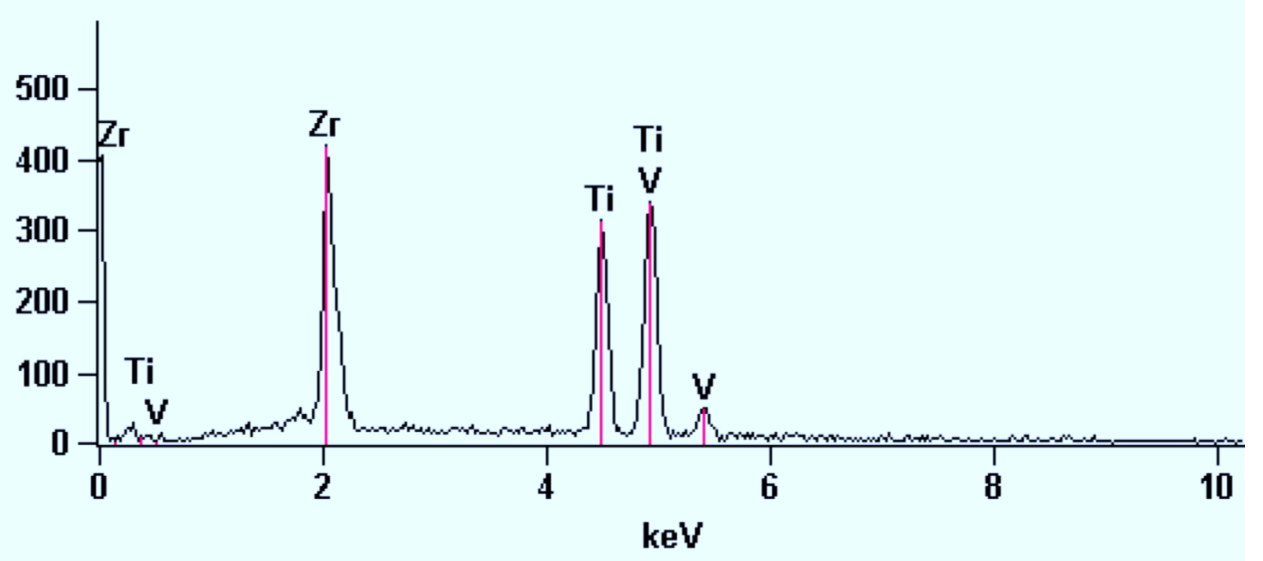

Figure 6. A typical EDX scan of the deposited NEG material.

\section{Using Permanent Magnets}

While a setup utilizing an air core solenoid is fairly easy to construct there are some significant drawbacks when very small or very large diameter cylinders are to be coated. 


\begin{tabular}{|c|c|c|c|c|c|c|}
\hline $\begin{array}{c}\text { Tube } \\
\text { Diameter } \\
(\mathrm{cm})\end{array}$ & $\begin{array}{c}\text { Cathode } \\
\text { Wire Diameter } \\
(\mathrm{mm})\end{array}$ & $\begin{array}{c}\text { Cathode } \\
\text { Wire Length } \\
(\mathrm{mm})\end{array}$ & Power & Voltage & Ar flow rate & Deposition rate \\
\hline 2.54 & 0.5 & 377.825 & 15 & $370-400$ & 150 & $7500 \pm 100$ \\
\hline 1.27 & 0.5 & 377.825 & 15 & $300-450$ & 150 & $10100 \pm 100$ \\
\hline
\end{tabular}

Table 2. Operating conditions and measured deposition rates for the external permanent magnet arrangement.

\subsection{Coating Thin Tubes}

Thin tubes require a high magnetic field, necessitating either a magnet with a large number of layers (with the corresponding increase in weight, power, and cooling requirements), or a significant increase in the current requirements (it is easy to see from Eq. 1.1 that the required current scales inversely with the radius). In principle these problems could be dealt with by reducing the diameter of the magnet bore, and thus using less tubing, which would translate into lower weight and lower cooling requirements. This, however, would require the use of smaller, non-standard, vacuum flanges on the tube ends, which in undesirable.

We devised an alternate method to allow coating of this tubes which relies on permanent, highfield, magnets, which are cheap and easily acquired. We arranged four permanent neodymium (N52 grade) rod magnets (each with $1.4 \mathrm{~T}$ residual magnetic field) with their magnetization axes parallel to each other around the tube to be coated, this arrangement creates an axial magnetic field on the symmetry axis, which coincides with the location of the cathode wires, ensuring the existence of the crossed electric and magnetic fields. The four magnets were mounted in a "clamshell" arrangement, with two magnets for each half, allowing the two halves to be clamped around the tube, without requiring a large opening between the magnets. Figure 7 shows a schematic of the clamshell arrangement in the separated state. The magnets were arranged such that they were at a distance of 0.9 " from the tube axis. The magnetic field at the center of the arrangement was measured to be $560 \mathrm{G}$, which would allow coating of tubes down to $4 \mathrm{~mm}$ in diameter (with $500 \mathrm{~V}$ operating voltage), note that the minimum chamber radius is in fact limited by the formation of dark spaces [8]. It is worth noting that in case a higher voltage is required the field can be increasing by decreasing the distance between the magnets, which is impossible when using a solenoid design. We have tested this design and have shown that a plasma discharge with the same parameters (power, current, and voltage) as when using the solenoid magnet can easily be achieved, ensuring the same deposition rate. Table 2 details the parameters used for the permanent magnet setup and the measured deposition rates. Figure 8 shows a picture of the permanent magnet arrangement around a 1" diameter tube (the permanent magnet arrangement is resting on top of the solenoid magnet, the difference is complexity and scale can this easily be seen). Figure 9 shows an EDX scan of the film deposited using the permanent magnet arrangement, comparison with Figure 6 shows nearly identical composition.

\subsection{Coating Large Bore Tubes}

The design of the clamshell arrangement may be scaled to accommodate larger diameter tubes by increasing the distance between the magnets. Note, however, that since the field from the 


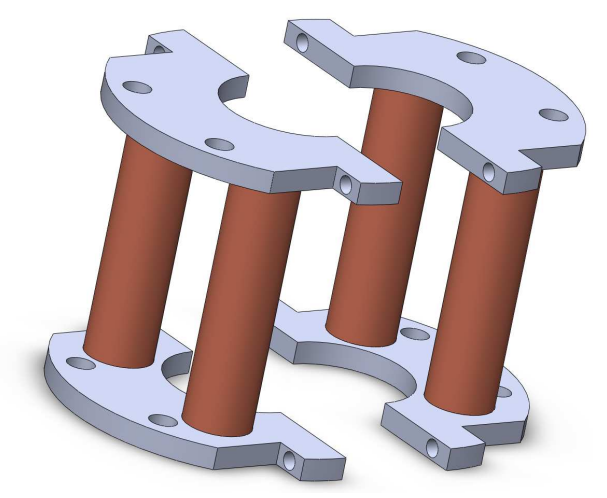

Figure 7. A schematic of the clamshell permanent magnet design, shown in the separated state.

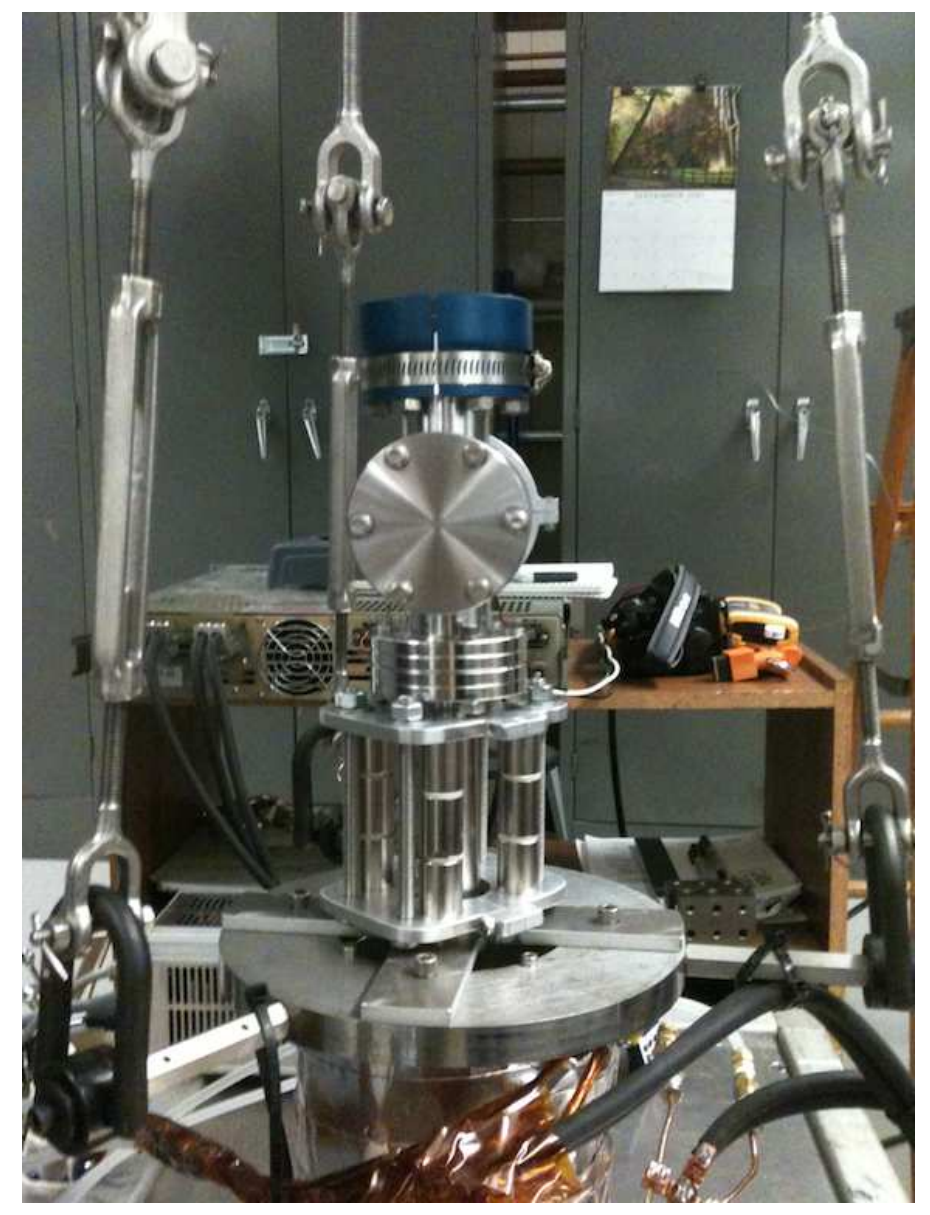

Figure 8. The clamshell permanent magnet design, resting on top of the solenoid.

rod magnets decreases faster than as the inverse of the distance, the number of magnets must be increased as the diameter grows. 


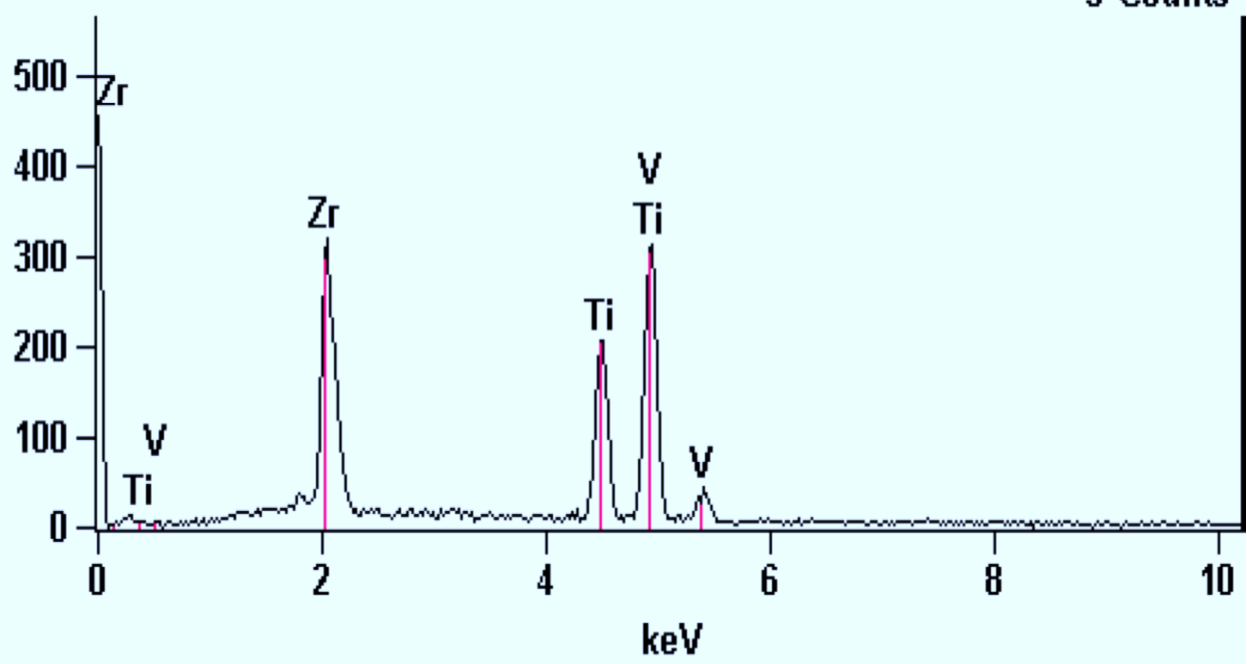

Figure 9. A typical EDX scan of the deposited NEG material using the permanent magnet arrangement.

An alternate method under development, which we intend to use for coating large diameter tubes, is to place the magnet internal to the vacuum chamber, surrounded by the cathode wires. A schematic of the proposed setup (cutaway) is shown in Figure 10. The permanent magnet is connected to a push-pull manipulator and free to slide inside a ceramic tube which runs the length of the chamber to be coated. The cathode wires are wound around the ceramic tube and likewise run the length of the chamber.

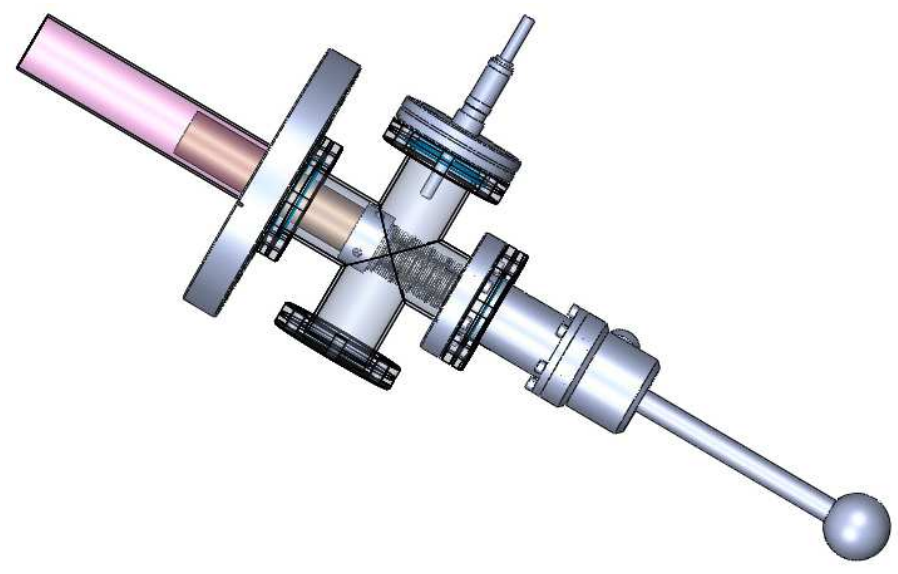

Figure 10. Design for an internal permanent magnet coating apparatus. The magnet (brown) is free to slide inside a ceramic tube (magenta). The cathode wires (not shown) are wound around the ceramic tube. 


\section{Summary}

In summary, we have constructed a high yield, apparatus for the NEG coating of very thin tubes, useful as differential pumping stages in a vacuum system. We have also demonstrated the possibility of using a very simple external permanent magnet arrangement to alleviate the need for a high field solenoid.

Finally, we are further testing the possibility of using an internal permanent magnet arrangement to coat large diameter tubes without the need for heavy and cumbersome electromagnet designs.

\section{Acknowledgements}

This work was supported by the Director, Office of Science, Office of Nuclear Physics, U.S. Department of Energy under Contract No. DE-AC02-05CH11231f. Part of this work was also supported by the Rothschild Fellowship administered by the Yad Hanadiv Foundation.

\section{References}

[1] G. Bregliozzi, et al., Proceedings of EPAC 2008, Genoa, Italy.

[2] R. Kersevan, Proceedings of EPAC 2002, Paris, France.

[3] C. Benvenuti, et al., Vacujm 60, 57 (2001).

[4] C. Benvenuti, et al., Vacujm 71, 307 (2003).

[5] A. Prodromides, $\mathrm{PhD}$ thesis (2002).

[6] Y. Wang, et al., Proceedings of PAC09, Vancouver, BC, Canada,.

[7] J. Thornton and A. Penfold, in Thin Film Processes, edited by J. Vossen and W. Kern, Academic Press, New York (1978) p. 92.

[8] S. Swann, Phys. Technol. 19, 67 (1988). 


\section{DISCLAIMER}

This document was prepared as an account of work sponsored by the United States Government. While this document is believed to contain correct information, neither the United States Government nor any agency thereof, nor the Regents of the University of California, nor any of their employees, makes any warranty, express or implied, or assumes any legal responsibility for the accuracy, completeness, or usefulness of any information, apparatus, product, or process disclosed, or represents that its use would not infringe privately owned rights. Reference herein to any specific commercial product, process, or service by its trade name, trademark, manufacturer, or otherwise, does not necessarily constitute or imply its endorsement, recommendation, or favoring by the United States Government or any agency thereof, or the Regents of the University of California. The views and opinions of authors expressed herein do not necessarily state or reflect those of the United States Government or any agency thereof or the Regents of the University of California. 